\title{
ANÁLISE DO DIÂMETRO DO HIPOCÓTILO EM PLANTAS DE SOJA
}

\author{
NOGUEIRA, João Pedro Garcia ${ }^{1}$ \\ CAMPOS, Núbia Soares de ${ }^{1}$ \\ CAMARGOS, Rayssa Veloso de Castro ${ }^{1}$ \\ BOMTEMPO, Gustavo Lourenço ${ }^{1}$ \\ FERREIRA, Silvana da Costa ${ }^{2}$ \\ CECON, Paulo Roberto ${ }^{3}$ \\ MATSUO, Eder ${ }^{4}$
}

RESUMO: Objetivou-se identificar diferença entre grupos de cultivares, estudar o efeito da profundidade de semeadura sobre o diâmetro do hipocótilo e o comportamento do diâmetro do hipocótilo ao longo do desenvolvimento das plantas de soja. Para isto analisou-se cultivares de soja em estádio inicial de desenvolvimento, em condições de casa de vegetação, quanto ao diâmetro do hipocótilo em dois sentidos: COT - sentido dos cotilédones e OPCOT - sentido oposto aos cotilédones. Os dados foram analisados por meio da análise de variância, teste de médias (Tukey ou Scott-Knott), regressão e correlação fenotípica e genotípica. E, estimados o coeficiente de variação e coeficiente de determinação genotípica. Verificou-se que as cultivares de soja se diferenciam quanto ao diâmetro do hipocótilo e identificou-se grande influência genética em detrimentos aos efeitos ambientais. Semeadura de 1 à $3 \mathrm{~cm}$ de profundidade não influenciou o diâmetro do hipocótilo, avaliados nos estádios V2 e V3, ao analisar plantas das cultivares TMG 4185, BRSMG 68 [Vencedora], BRS 7980 e BRS 8381. As cultivares 98Y30, TMG1174RR e TMG 4185 apresentaram comportamento semelhantes quanto ao diâmetro do hipocótilo no período de 0 à 48 dias após o estádio de desenvolvimento V1.

Palavras-Chave: Glycine max. Melhoramento. Distinguibilidade.

\section{ANALYSIS OF THE HYPOCOTYL DIAMETER IN SOYBEAN PLANTS}

SUMMARY: The objective of this study was to identify differences between groups of cultivars, to study the effect of sowing depth on the hypocotyl diameter and the behavior of the hypocotyl diameter throughout the development of soybean plants. For this, soybean cultivars were analyzed at initial development stage, under greenhouse conditions, regarding hypocotyl diameter in two senses: COT - in the sense of cotyledons and OPCOT - opposite to cotyledons. Data were analyzed through analysis of variance, test of averages (Tukey or Scott-Knott), regression and phenotypic and genotypic correlation. And, coefficient of variation and coefficient of genotypic determination. It was verified that the soybean cultivars differ in the diameter of the hypocotyl and a great genetic influence was identified in detriment to the environmental effects. Seeding of 1 to $3 \mathrm{~cm}$ of depth did not influence the hypocotyl diameter, evaluated in stages V2 and V3, when analyzing plants of the cultivars TMG 4185, BRSMG 68 [Vencedora], BRS 7980 and BRS 8381. The cultivars 98Y30, TMG1174RR and TMG 4185 presented similar behavior regarding the hypocotyl diameter in the period from 0 to 48 days after the V1 development stage.

Keywords: Glycine max. Breeding. Distinguishability.

\footnotetext{
${ }^{1}$ Instituto de Ciências Agrárias, Campus Rio Paranaíba, Universidade Federal de Viçosa

${ }^{2}$ Instituto de Ciências Biológicas e da Saúde, Campus Rio Paranaíba, Universidade Federal de Viçosa

${ }^{3}$ Departamento de Estatística, Centro de Ciências Exatas e Tecnológicas, Campus Viçosa, Universidade Federal de Viçosa

${ }^{4}$ Instituto de Ciências Exatas e Tecnológicas, Campus Rio Paranaíba, Universidade Federal de Viçosa
} 


\section{INTRODUÇÃO}

A cultura da soja (Glycine max (L.) Merr.) destaca-se no cenário do agronegócio nacional como uma das principais culturas, principalmente quanto à exportação e geração de produto interno bruto. Parte do grande sucesso da soja no Brasil, deve-se aos programas de melhoramento genético de várias instituições de pesquisa e universidades brasileiras (ODA et al., 2015).

Um marco importante para a agricultura brasileira, em especial a cultura da soja, foi a promulgação da Lei n. 9.456 (Lei de Proteção de Cultivares - LPC) regulamentada pelo Decreto n. 2.366 (de 5 de novembro de 1997) que garante os direitos dos obtentores de novas variedades vegetais (FERRAZ; CAMPOS et al., 2009). No Brasil, em outubro de 2018, há 912 cultivares de soja protegidas (MAPA/SNPC, 2018).

Nogueira et al. (2008) reportaram, à época, que os descritores obrigatórios e adicionais utilizados na diferenciação de cultivares de soja eram insuficientes para a distinguibilidade, o que tornou de acordo com os autores, evidente a necessidade de ampliar a lista de descritores utilizados. Posteriormente, outros estudos foram desenvolvidos com o intuito de melhor entendimento de caracteres que pudessem ser utilizados como descritores, como os manuscritos de Matsuo et al. (2012a), Matsuo et al. (2012b), Silva et al. (2016), Dias et al. (2017) e Chaves et al. (2017).

Para diâmetro do hipocótilo, Silva et al. (2016) identificaram variabilidade genética entre 10 cultivares de soja e reportaram grande influência genética para esta variável. A existência de variabilidade genética é condição necessária para que uma característica possa ser útil na diferenciação de cultivares (Nogueira et al., 2008). Tornando-se, assim, necessário a identificação da existência desta variabilidade em outros grupos de cultivares. Além de identificar diferenças entre médias, pode-se estimar o coeficiente de determinação genotípico $\left(\mathrm{H}^{2}\right)$, isto porque o $\mathrm{H}^{2}$ é uma medida análoga à herdabilidade e expressa a variância fenotípica devida à variabilidade genética entre as médias dos tratamentos (CRUZ, 2005). Estudos que estimaram o $\mathrm{H}^{2}$ destacam-se os de Nogueira et al. (2008), Matsuo et al. (2012a) e Silva et al. (2016) que analisaram caracteres fenotípicos nas fases iniciais do desenvolvimento da soja e de Vasconcelos et al. (2012) que estimaram parâmetros genéticos da qualidade fisiológica de sementes de genótipos de soja produzidas em diferentes regiões de Minas Gerais.

O hipocótilo das plântulas de soja responde às resistências físicas com a diminuição do tamanho e o aumento do diâmetro (KNITTLE ; BURRIS, 1979). Isto é, o comprimento e IER (que é proporcional ao diâmetro) do hipocótilo das plântulas são medidas do crescimento que estão relacionadas com a capacidade das mesmas em emergir, vencendo esta barreira, uma vez que o hipocótilo deve crescer em comprimento, de modo a superar a profundidade de semeadura, e em diâmetro para aumentar sua força e habilidade de suportar, sem deformações, as resistências causadas pelo peso dos cotilédones e pelo encrostamento do solo (COSTA et al., 1999). Neste sentido, estudos tornam-se necessário para verificar se esta resposta ocorre quanto as sementes são plantadas à diferentes profundidades e se há comportamentos diferenciados de cultivares frente às variações da profundidade de plantio.

Neste contexto, analisar-se-á o diâmetro do hipocótilo com maiores detalhes, por isto, objetivou-se identificar a existência de diferença entre grupos de cultivares, estudar o efeito da profundidade de semeadura sobre o diâmetro do hipocótilo e o comportamento do diâmetro do hipocótilo ao longo do desenvolvimento das plantas de soja.

\section{MATERIAL E MÉTODO}

Os experimentos foram conduzidos em condições de casa de vegetação (19¹1'39"S; 46²14'37"W, 
1133 m de altitude) nas dependências da Universidade Federal de Viçosa - Campus Rio Paranaíba, no município de Rio Paranaíba, Minas Gerais. Foram conduzidos quatro experimentos, conforme descrição abaixo, com o intuito de analisar o diâmetro do hipocótilo (DH) na posição central entre o solo e o nó cotiledonar em dois sentidos (COT - sentido dos cotilédones e OPCOT - sentido oposto aos cotilédones) utilizando-se de paquímetro digital (em mm, com precisão de duas casas decimais).

Experimento 1. Foram avaliadas plantas de seis cultivares de soja (BRSGO8660, BRS7980, BRSMG 68 [Vencedora], UFVTN105AP, TMG4182 e BRS313 [Tieta]), nos meses de novembro à dezembro. Para a semeadura, utilizou-se sementes de tamanho aleatório, as quais foram plantadas à $2 \mathrm{~cm}$ de profundidade em vaso de $3 \mathrm{dm}^{3}$ contendo solo e matéria orgânica. No estádio de desenvolvimento V1 (FEHR e CAVINESS, 1977), procedeu-se o desbaste mantendo três plantas por vasos. As plantas foram conduzidas conforme recomendação da cultura. No estádio de desenvolvimento V2 e V3, avaliou-se o DH-COT e DH-OPCOT. Foi considerado o delineamento em blocos casualizados com cinco repetições, sendo que cada unidade experimental foi composta por três plantas e usou-se a média da parcela (unidade experimental) na análise dos dados. Procedeu-se a análise de variância, obteve-se a estimativa do coeficiente de variação experimental, coeficiente de determinação genotípico e as médias, quanto necessárias, foram comparadas pelo teste de Tukey $(\alpha=0,05)$.

Experimento 2. Foram avaliadas plantas de vinte e oito cultivares de soja (BRS Candeia, BRS Carnaúba, BRS Tracajá, BRS 283, BRS 284, MG/BR 46 (Conquista), P98C81, BRS313 [Tieta], TMG 803, M-SOY 8757, BRSGO 8660, FTM Tucunaré, TMG 4185, BRS 8381, BRSGO 8360, TMG 801, TMG 4182, AN 8500, BRSMG 810C, BRSMG 68 [Vencedora], BRSGO 7960, BRS 7980, BRSGO 7560, BRSMG 752 S, FT Cristalina, TMG 401, CD 201 e CD 202) nos meses de maio à junho. Para a semeadura utilizou-se sementes de tamanho aleatório, as quais foram plantadas à $2 \mathrm{~cm}$ de profundidade em vaso de $3 \mathrm{dm}^{3}$ contendo solo e matéria orgânica. No estádio de desenvolvimento $\mathrm{V} 1$, procedeu-se o desbaste mantendo duas plantas por vasos. As plantas foram conduzidas conforme recomendação da cultura. No estádio de desenvolvimento V2 e V3, avaliou-se o DH-COT e DH-OPCOT. Foi considerado o delineamento em blocos casualizados com quatro repetições, sendo que cada unidade experimental foi composta por duas plantas e usou-se a média da parcela na análise do dados. Procedeu-se a análise de variância, obteve-se a estimativa do coeficiente de variação experimental, coeficiente de determinação genotípico e, quando necessárias, as médias foram agrupadas pelo teste de agrupamento de Scott-Knott ( $\alpha$ $=0,05)$. Adicionalmente, foram estimadas as correlações fenotípicas e genotípicas entre as variáveis respostas. A significância da correlação fenotípica foi estimada pelo teste t com n-2 graus de liberdade, em que $\mathrm{n}$ corresponde ao número de cultivares avaliadas. A significância das correlações genotípicas foi avaliada pelo bootstrap com cinco mil simulações.

Experimento 3. Foram avaliadas plantas de quatro cultivares de soja (TMG 4185, BRSMG 68 [Vencedora], BRS 7980 e BRS 8381) em função de três profundidades de plantio (1, 2 e $3 \mathrm{~cm})$, no meses de outubro à novembro. Para a semeadura, utilizou-se sementes de tamanho aleatório, as quais foram plantadas em vaso de $3 \mathrm{dm}^{3}$ contendo solo e matéria orgânica. No estádio de desenvolvimento V1 (FEHR; CAVINESS, 1977), procedeu-se o desbaste mantendo três plantas por vasos. As plantas foram conduzidas conforme recomendação da cultura. No estádio de desenvolvimento V2 e V3, avaliou-se o DH-COT e DH-OPCOT. Foi considerado um esquema fatorial 4 × 3 no delineamento em blocos ao acaso com seis repetições. Cada unidade experimental foi composta por três plantas e usou-se a média da parcela na análise dos dados. Posteriormente, obteve-se a estimativa do coeficiente de variação experimental e as médias, quando necessário, foram comparadas pelo teste de Tukey $(\alpha=0,05)$.

Experimento 4. Foram avaliadas plantas de três cultivares de soja (98Y30, TMG1174RR e TMG4185) em função de oito épocas de avaliação $(0,7,14,21,28,35,42$ e 48 dias após o Estádio de 
Desenvolvimento V1 - DAV1), nos meses de outubro à dezembro, quanto ao DH-COT e DH-OPCOT. Para a semeadura, utilizou-se sementes de tamanho aleatório, as quais foram plantadas a $2 \mathrm{~cm}$ de profundidade em vaso de $3 \mathrm{dm}^{3}$ contendo solo e matéria orgânica. No estádio de desenvolvimento VC, desbastou-se as plantas mantendo uma por vasos. Para efeito de análise estatística, foi utilizado o esquema em parcela subdividida, em que as parcelas foram compostas pelas cultivares e as subparcelas pelas épocas de avaliação, no delineamento em blocos casualizados, com seis repetições. Cada unidade experimental foi composta por uma planta cultivada em um vaso. Os dados foram analisados por meio de análise de variância, obteve-se a estimativa do coeficiente de variação experimental. A comparação das médias entre cultivares foi realizada por meio do teste de Tukey $(\alpha=0,05)$ e a análise das médias das épocas de avaliação dentro de cada cultivar, separadamente para cada variável analisada, foram realizadas por meio da análise de regressão.

As análises estatísticas dos quatro experimentos foram realizadas no Programa Genes (CRUZ, 2013) e SAEG (SAEG, 2007).

\section{RESULTADO E DISCUSSÃO}

Efeito significativo para Cultivares foi identificado nos caracteres diâmetro do hipocótilo no sentido dos cotilédones (DH-COT) e no sentido oposto aos cotilédones (DH-OPCOT), obtidos nos estádios de desenvolvimento V2 e V3. Os valores de coeficientes de variação oscilaram de 6,15 à 9,14\% para DH-COT-V2, de 5,47 à 9,22 para DH-OPCOT-V2, de 6,16 à 8,16\% para DH-COT-V3 e de 6,55 à $8,00 \%$ para DH-OPCOT-V3. A magnitude do coeficiente de determinação genotípico variou de $74 \%$ à $86 \%$ (Tabela 1).

Tabela 1. Resumo da análise de variância do diâmetro do hipocótilo (DH) mensurados no sentido dos cotilédones (COT) e no sentido oposto aos cotilédones (OPCOT), nos estádios de desenvolvimento V2 e V3, de plantas de soja, nos experimentos 1 e 2, conduzidos em condições de casa de vegetação, com informações adicionais de coeficiente de variação $\left(\mathrm{CV}_{\%}\right)$ e coeficiente de determinação genotípico $\left(\mathrm{H}_{(\%)}^{2}\right)^{1}$

\begin{tabular}{|c|c|c|c|c|c|}
\hline \multirow{2}{*}{ FV } & \multirow{2}{*}{ GL } & \multicolumn{2}{|c|}{ Estádio V2 } & \multicolumn{2}{|c|}{ Estádio V3 } \\
\hline & & DH-COT & DH-OPCOT & DH-COT & DH-OPCOT \\
\hline \multicolumn{6}{|c|}{ Experimento 1} \\
\hline Blocos & 4 & 0,0147 & 0,0879 & 0,0399 & 0,0938 \\
\hline Cultivares & 5 & $0,3981 * *$ & $0,6871 * *$ & $0,6196 * *$ & $0,6263 * *$ \\
\hline Resíduo & 20 & 0,0789 & 0,0926 & 0,1196 & 0,1231 \\
\hline Media & & 3,0723 & 3,2977 & 4,2357 & 4,3833 \\
\hline $\mathrm{CV}_{\%}$ & & 9,14 & 9,22 & 8,16 & 8,00 \\
\hline $\mathrm{H}_{(\%)}^{2}$ & & 80,19 & 86,52 & 80,70 & 80,34 \\
\hline \multicolumn{6}{|c|}{ Experimento 2} \\
\hline Blocos & 3 & 0,0120 & 0,0053 & 0,0277 & 0,0025 \\
\hline Cultivares & 27 & $0,1481 * *$ & $0,1796 * *$ & $0,2964 * *$ & $0,2486 * *$ \\
\hline Resíduo & 81 & 0,0326 & 0,0303 & 0,0463 & 0,0642 \\
\hline Media & & 2,9352 & 3,1781 & 3,4912 & 3,8651 \\
\hline $\mathrm{CV}_{\%}$ & & 6,15 & 5,47 & 6,16 & 6,55 \\
\hline $\mathrm{H}_{(\%)}^{2}$ & & 77,98 & 83,13 & 84,38 & 74,17 \\
\hline
\end{tabular}

1/**: Significativo à $1 \%$ de probabilidade pelo teste $\mathrm{F}$.

Foi identificado diferença entre as médias quando analisadas seis cultivares de soja (Tabela 2). Observou-se comportamento semelhante das cultivares ao serem analisadas quanto ao DH-COT-V2 e DH- 
OPCOTV3, sendo que o cultivar UFVTN 105 AP foi superior aos BRSGO 8660, TMG 4182 e BRS 313 respectivamente. A cultivar UFVTN 105 AP e TMG 4182 destacaram-se, de maneira geral, respectivamente, como uma das maiores e menores médias.

Tabela 2.Médias do diâmetro do hipocótilo (DH) mensurados no sentido dos cotilédones (COT) e no sentido oposto aos cotilédones (OPCOT), nos estádios de desenvolvimento V2 e V3, de plantas de seis cultivares de soja, conduzidos em condições de casa de vegetação ${ }^{1}$

\begin{tabular}{llcllc}
\hline \multirow{2}{*}{ Cultivares } & \multicolumn{3}{c}{ Estádio V2 } & \multicolumn{3}{c}{ Estádio V3 } \\
\cline { 2 - 6 } & DH-COT & DH-OPCOT & DH-COT & DH-OPCOT \\
\hline BRSGO 8660 & $2,86 \mathrm{~b}$ & $3,13 \mathrm{bc}$ & $3,98 \mathrm{~b}$ & $4,16 \mathrm{~b}$ \\
BRS 7980 & $3,06 \mathrm{ab}$ & $3,25 \mathrm{bc}$ & $4,16 \mathrm{ab}$ & $4,26 \mathrm{ab}$ \\
BRSMG 68 [Vencedora] & $3,23 \mathrm{ab}$ & $3,54 \mathrm{ab}$ & $4,56 \mathrm{ab}$ & $4,71 \mathrm{ab}$ \\
UFVTN 105 AP & $3,55 \mathrm{a}$ & $3,91 \mathrm{a}$ & $4,77 \mathrm{a}$ & $4,93 \mathrm{a}$ \\
TMG 4182 & $2,82 \mathrm{~b}$ & $2,92 \mathrm{c}$ & $3,95 \mathrm{~b}$ & $4,06 \mathrm{~b}$ \\
BRS 313 [Tieta] & $2,89 \mathrm{~b}$ & $3,01 \mathrm{bc}$ & $3,97 \mathrm{~b}$ & $4,16 \mathrm{~b}$ \\
\hline
\end{tabular}

${ }^{1 /}$ Médias seguidas pela mesma letra minúscula na coluna não diferem entre si, pelo método de Tukey $(\alpha=0,05)$.

Ao analisar 28 cultivares (Tabela 3), verificou-se a formação de dois grupos para as avaliações realizadas em V2 e três grupos em V3, independente se a medição foi realizada no sentido dos cotilédones ou no sentido opostos aos cotilédones.

Tabela 3. Médias do diâmetro do hipocótilo (DH) mensurados no sentido dos cotilédones (COT) e no sentido oposto aos cotilédones (OPCOT), nos estádios de desenvolvimento V2 e V3, de plantas de 28 cultivares de soja, conduzidos em condições de casa de vegetação ${ }^{1}$

\begin{tabular}{lccccc}
\hline \multirow{2}{*}{ Cultivares } & \multicolumn{3}{c}{ Estádio V2 } & \multicolumn{3}{c}{ Estádio V3 } \\
\cline { 2 - 7 } & DH-COT & DH-OPCOT & DH-COT & DH-OPCOT \\
\hline BRS Candeia & $3,12 \mathrm{a}$ & $3,34 \mathrm{a}$ & $3,68 \mathrm{~b}$ & $4,00 \mathrm{~b}$ \\
BRS Carnaúba & $3,29 \mathrm{a}$ & $3,59 \mathrm{a}$ & $3,81 \mathrm{~b}$ & $4,33 \mathrm{a}$ \\
BRS Tracajá & $2,70 \mathrm{~b}$ & $2,85 \mathrm{~b}$ & $3,26 \mathrm{c}$ & $3,42 \mathrm{c}$ \\
BRS 283 & $2,88 \mathrm{~b}$ & $3,07 \mathrm{~b}$ & $3,29 \mathrm{c}$ & $3,59 \mathrm{c}$ \\
BRS 284 & $2,88 \mathrm{~b}$ & $3,27 \mathrm{a}$ & $3,33 \mathrm{c}$ & $3,81 \mathrm{c}$ \\
MG/BR 46 (Conquista) & $2,96 \mathrm{~b}$ & $3,25 \mathrm{a}$ & $3,36 \mathrm{c}$ & $3,86 \mathrm{c}$ \\
P98C81 & $3,22 \mathrm{a}$ & $3,44 \mathrm{a}$ & $3,83 \mathrm{~b}$ & $4,09 \mathrm{~b}$ \\
BRS 313 (Tieta) & $2,62 \mathrm{~b}$ & $2,98 \mathrm{~b}$ & $3,30 \mathrm{c}$ & $3,64 \mathrm{c}$ \\
TMG 803 & $3,22 \mathrm{a}$ & $3,38 \mathrm{a}$ & $4,11 \mathrm{a}$ & $4,34 \mathrm{a}$ \\
M-SOY 8757 & $2,78 \mathrm{~b}$ & $3,06 \mathrm{~b}$ & $3,26 \mathrm{c}$ & $3,73 \mathrm{c}$ \\
BRSGO 8660 & $2,81 \mathrm{~b}$ & $3,15 \mathrm{~b}$ & $3,45 \mathrm{c}$ & $3,89 \mathrm{c}$ \\
FTM Tucunaré & $2,81 \mathrm{~b}$ & $2,94 \mathrm{~b}$ & $3,50 \mathrm{c}$ & $3,67 \mathrm{c}$ \\
TMG 4185 & $2,89 \mathrm{~b}$ & $3,10 \mathrm{~b}$ & $3,53 \mathrm{c}$ & $3,81 \mathrm{c}$ \\
BRS 8381 & $2,82 \mathrm{~b}$ & $2,92 \mathrm{~b}$ & $3,22 \mathrm{c}$ & $3,57 \mathrm{c}$
\end{tabular}


Tabela 3. Médias do diâmetro do hipocótilo (DH) mensurados no sentido dos cotilédones (COT) e no sentido oposto aos cotilédones (OPCOT), nos estádios de desenvolvimento V2 e V3, de plantas de 28 cultivares de soja, conduzidos em condições de casa de vegetação ${ }^{1}$

\begin{tabular}{lcccc}
\hline \multirow{2}{*}{ Cultivares } & \multicolumn{3}{c}{ Estádio V2 } & \multicolumn{3}{c}{ Estádio V3 } \\
\cline { 2 - 6 } & DH-COT & DH-OPCOT & DH-COT & DH-OPCOT \\
\hline BRSGO 8360 & $2,91 \mathrm{~b}$ & $3,33 \mathrm{a}$ & $3,37 \mathrm{c}$ & $3,83 \mathrm{c}$ \\
TMG 801 & $3,07 \mathrm{a}$ & $3,28 \mathrm{a}$ & $3,61 \mathrm{~b}$ & $3,99 \mathrm{~b}$ \\
TMG 4182 & $2,72 \mathrm{~b}$ & $2,90 \mathrm{~b}$ & $3,26 \mathrm{c}$ & $3,72 \mathrm{c}$ \\
AN 8500 & $2,72 \mathrm{~b}$ & $2,94 \mathrm{~b}$ & $3,34 \mathrm{c}$ & $3,70 \mathrm{c}$ \\
BRSMG 810C & $2,94 \mathrm{~b}$ & $3,15 \mathrm{~b}$ & $3,44 \mathrm{c}$ & $3,88 \mathrm{c}$ \\
BRSMG 68 [Vencedora] & $2,79 \mathrm{~b}$ & $3,08 \mathrm{~b}$ & $3,18 \mathrm{c}$ & $3,75 \mathrm{c}$ \\
BRSGO 7960 & $3,09 \mathrm{a}$ & $3,36 \mathrm{a}$ & $3,75 \mathrm{~b}$ & $3,98 \mathrm{~b}$ \\
BRS 7980 & $2,76 \mathrm{~b}$ & $2,99 \mathrm{~b}$ & $3,10 \mathrm{c}$ & $3,59 \mathrm{c}$ \\
BRSGO 7560 & $2,80 \mathrm{~b}$ & $3,00 \mathrm{~b}$ & $3,25 \mathrm{c}$ & $3,77 \mathrm{c}$ \\
BRSMG 752 S & $3,14 \mathrm{a}$ & $3,44 \mathrm{a}$ & $3,67 \mathrm{~b}$ & $4,10 \mathrm{~b}$ \\
FT Cristalina & $2,76 \mathrm{~b}$ & $3,06 \mathrm{~b}$ & $3,36 \mathrm{c}$ & $3,68 \mathrm{c}$ \\
TMG 401 & $3,20 \mathrm{a}$ & $3,44 \mathrm{a}$ & $4,12 \mathrm{a}$ & $4,37 \mathrm{a}$ \\
CD 201 & $3,08 \mathrm{a}$ & $3,19 \mathrm{~b}$ & $3,52 \mathrm{c}$ & $3,87 \mathrm{c}$ \\
CD 202 & $3,21 \mathrm{a}$ & $3,58 \mathrm{a}$ & $3,85 \mathrm{~b}$ & $4,28 \mathrm{a}$
\end{tabular}

${ }^{1 /}$ Médias seguidas pela mesma letra minúscula na coluna na coluna formam um grupo homogêneo, pelo método de agrupamento de Scott-Knott $(\alpha=0,05)$

$\mathrm{O}$ efeito de interação cultivares $\mathrm{x}$ profundidades e de profundidades (isoladamente) foram não significativos (Tabela 4). Isto indica que as médias de diâmetro do hipocótilo das cultivares analisadas não apresentam comportamento diferenciado nas diferentes profundidades e, também, que o efeito isolado de profundidade não implicou em diferença entre as três médias de DH provenientes do plantio realizado à 1 , 2 e $3 \mathrm{~cm}$. Assim, não houve efeito de profundidade sobre o diâmetro do hipocótilo, quando analisados no sentido dos cotilédones ou no sentido oposto aos cotilédones. No entanto, o efeito isolado de cultivares foi significativo nas quatro variáveis analisadas, com coeficientes de variação iguais à 13,74, 16,42, 12,14 e $11,78 \%$, respectivamente para DH-COT-V2, DH-OPCOT-V2, DH-COT-V3 e DH-OPCOT-V3.

Tabela 4. Resumo da análise de variância do diâmetro do hipocótilo (DH) mensurados no sentido dos cotilédones (COT) e no sentido oposto aos cotilédones (OPCOT), nos estádios de desenvolvimento V2 e V3, de plantas de soja, no experimento 3, conduzidos em condições de casa de vegetação ${ }^{1}$

\begin{tabular}{|c|c|c|c|c|c|}
\hline \multirow{2}{*}{ FV } & \multirow{2}{*}{ GL } & \multicolumn{2}{|c|}{ Estádio V2 } & \multicolumn{2}{|c|}{ Estádio V2 } \\
\hline & & DH-COT & DH-OPCOT & DH-COT & DH-OPCOT \\
\hline Blocos & 5 & 0,1432 & 0,1138 & 0,2012 & 0,3105 \\
\hline Cultivares (C) & 3 & $0,5763 * *$ & $0,6246 *$ & $0,7090 * *$ & $0,8690 * *$ \\
\hline Profundidades $(\mathrm{P})$ & 2 & 0,0923 ns & $0,0426^{\mathrm{ns}}$ & $0,4216^{\mathrm{ns}}$ & $0,2428 \mathrm{~ns}$ \\
\hline $\mathrm{C} \times \mathrm{P}$ & 6 & 0,1189 ns & $0,1574 \mathrm{~ns}$ & 0,0769 ns & 0,0653 ns \\
\hline Resíduo & 55 & 0,1267 & 0,2085 & 0,1355 & 0,1462 \\
\hline Média & & 2,58 & 2,77 & 3,03 & 3,24 \\
\hline $\mathrm{CV}_{\%}$ & & 13,74 & 16,42 & 12,14 & 11,78 \\
\hline
\end{tabular}

$1 / * * \mathrm{e} *$ Significativos a 1 e $5 \%$ de probabilidade; respectivamente; pelo teste $\mathrm{F}$; ${ }^{\text {ns }}$ : Não-significativo. 
Por meio do teste de Tukey (Tabela 5), observou-se que a cultivar BRS7980 diferiu-se da BRS8381 em DH-COT-V2 e das cultivares BRSMG 68 [Vencedora] e BRS8381 e já para DH-OPCOTV3 a BRSMG68 e BRS7980 diferem da BRS 8381.

Tabela 5. Médias do diâmetro do hipocótilo (DH) mensurados no sentido dos cotilédones (COT) e no sentido oposto aos cotilédones (OPCOT), nos estádios de desenvolvimento V2 e V3, de plantas de quatro cultivares de soja, conduzidos em condições de casa de vegetação ${ }^{1}$

\begin{tabular}{lllllll}
\hline \multirow{2}{*}{ Cultivares } & \multicolumn{3}{c}{ Estádio V2 } & \multicolumn{3}{c}{ Estádio V2 } \\
\cline { 2 - 6 } & DH-COT & DH-OPCOT & DH-COT & DH-OPCOT \\
\hline TMG 4185 & $2,61 \mathrm{ab}$ & $2,91 \mathrm{a}$ & $3,03 \mathrm{ab}$ & $3,30 \mathrm{ab}$ \\
BRSMG 68 [Vencedora] & $2,59 \mathrm{ab}$ & $2,60 \mathrm{a}$ & $3,11 \mathrm{a}$ & $3,16 \mathrm{~b}$ \\
BRS 7980 & $2,79 \mathrm{a}$ & $2,96 \mathrm{a}$ & $3,22 \mathrm{a}$ & $3,51 \mathrm{a}$ \\
BRS 8381 & $2,35 \mathrm{~b}$ & $2,63 \mathrm{a}$ & $2,75 \mathrm{~b}$ & $2,99 \mathrm{~b}$ \\
\hline
\end{tabular}

${ }^{1 /}$ Médias seguidas pela mesma letra minúscula na coluna não diferem entre si, pelo método de Tukey $(\alpha=0,05)$.

Efeitos significativos foram identificados para a interação entre cultivares e épocas de avaliação do DH-COT e DH-OPCOT em plantas de soja. Isto indica que ao fixar a cultivar, as médias de DH-COT e DH-OPCOT, se diferiram ao longo das épocas de avalição e dentro de cada época, as cultivares apresentaram médias distintas (Tabela 6). Os valores de coeficientes de variação para DH-COT foram de 13,28 e $5,05 \%$, respectivamente, para Parcela e Subparcela, enquanto que para DH-OPCOT foram de $11,71 \%$ para Parcela e $3,96 \%$ para Subparcela.

Tabela 6. Resumo da análise de variância do diâmetro do hipocótilo (DH) mensurados no sentido dos cotilédones (COT) e no sentido oposto aos cotilédones (OPCOT), de plantas de soja, no experimento 4, conduzidos em condições de casa de vegetação, com informação adicional de coeficiente de variação $\left(\mathrm{CV}_{\%}\right)^{1}$

\begin{tabular}{cccc}
\hline FV & GL & DH-COT & DH-OPCOT \\
\hline Blocos & 6 & 0,5286 & 0,7678 \\
Cultivares (C) & 2 & $0,3794^{\mathrm{ns}}$ & $0,3905^{\mathrm{ns}}$ \\
Resíduo a & 12 & 0,4514 & 0,4341 \\
Épocas (E) & 7 & $94,7094^{* *}$ & $128,6402^{* *}$ \\
Interação C x E & 14 & $0,1241^{*}$ & $0,1434 * *$ \\
Erro b & 126 & 0,0654 & 0,0498 \\
\hline Média & & 5,05 & 5,62 \\
\hline CV - Parcela & & 13,28 & 3,71 \\
CV $_{\%}$ - SUB-Parcela & & 5,05 & 3,96 \\
\hline
\end{tabular}

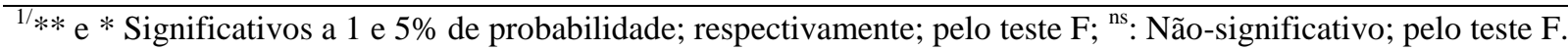

O desdobramento das médias do DH-COT das cultivares dentro de cada uma das épocas de avaliação indicou média distintas a partir de 42 dias após V1, enquanto que para DH-OPCOT as cultivares diferenciaram-se a partir de 35 dias após V1 (Tabela 7). Isto demonstra que, as cultivares não se diferenciaram quanto aos caracteres analisados nas etapas iniciais após V1. No entanto, ao analisar os resultados dos demais experimentos, pôde-se identificar diferença entre as médias das cultivares 
nas etapas inicias de desenvolvimento da planta de soja (Estádios V2 e V3).

Tabela 7. Desdobramento das medias do diâmetro do hipocótilo (DH) obtidos em oito épocas de avalição em função de três cultivares de soja, mensurados no sentido dos cotilédones (COT) e no sentido oposto aos cotilédones (OPCOT), em condições de casa de vegetação ${ }^{1}$

\begin{tabular}{|c|c|c|c|c|c|c|c|c|}
\hline \multirow{2}{*}{ Cultivares } & \multicolumn{8}{|c|}{ Épocas de avaliação - DH-COT } \\
\hline & $\mathrm{V} 1+0 \mathrm{D}^{2}$ & V1+7D & V1+14D & V1+21D & V1+28D & V1+35D & V1+42D & V1+48D \\
\hline $98 Y 30$ & 2,55 a & 2,85 a & 3,34 a & 4,49 a & 5,37 a & 6,70 a & 7,58 a & 8,20 a \\
\hline TMG 1174 RR & $2,63 \mathrm{a}$ & $2,78 \mathrm{a}$ & 3,30 a & $4,21 \mathrm{a}$ & 5,27 a & 6,85 a & 7,54 a & $7,99 \mathrm{ab}$ \\
\hline TMG & 2,49 a & 2,84 a & 3,37 a & 4,31 a & 5,35 a & 6,60 a & $7,09 \mathrm{~b}$ & $7,72 \mathrm{~b}$ \\
\hline \multirow{2}{*}{ Cultivares } & \multicolumn{8}{|c|}{ Épocas de avaliação - DH-OPCOT } \\
\hline & V1+0D & V1+7D & V1+14D & $V 1+21 D$ & V1+28D & V1+35D & V1+42D & V1+48D \\
\hline $98 Y 30$ & $2,56 \mathrm{a}$ & 3,03 a & $3,62 \mathrm{a}$ & $4,81 \quad \mathrm{a}$ & $6,10 \mathrm{a}$ & $7,65 \mathrm{~b}$ & $8,05 \mathrm{~b}$ & $8,60 \mathrm{~b}$ \\
\hline TMG 1174 RR & 2,74 a & 3,04 a & 3,64 a & 4,75 a & 5,95 a & 8,08 a & 8,51 a & 9,02 a \\
\hline TMG 4185 & 2,54 a & 2,94 a & 3,62 a & 4,74 a & 6,07 a & $7,90 \mathrm{ab}$ & 8,45 a & $8,56 \mathrm{~b}$ \\
\hline
\end{tabular}

${ }^{1 /}$ Médias seguidas pela mesma letra minúscula na coluna, separadamente para DH-COT e DH-OPCOT, não diferem entre si, pelo método de Tukey $(\alpha=0,05) .{ }^{2 /} \mathrm{V} 1+0 \mathrm{D}$ : 0 dias após o estádio de desenvolvimento V1.

À medida que se aumento o número de dias após o estádio V1, ocorreu aumento exponencial do diâmetro do hipocótilo (tanto para DH-COT quanto para DH-OPCOT) (Tabela 8). As cultivares apresentaram comportamento semelhante ao analisar isoladamente as respostas para DH-COT e DHOPCOT.

Tabela 8. Evolução do diâmetro do hipocótilo em função das épocas de avaliação

\begin{tabular}{cccc}
\hline Caracteres $^{1}$ & Cultivares & Modelo de regressão exponencial & $\mathbf{R}^{2}$ \\
\hline COT & 98 Y30 & $\hat{Y}=13,6 /\left(1+5,00032 e^{-0,04311 D}\right)$ & $R^{2}=0,99$ \\
COT & TMG 1174 RR & $\hat{Y}=13,12 /\left(1+4,9126 e^{-0,04396 D}\right)$ & $R^{2}=0,98$ \\
COT & TMG 4185 & $\hat{Y}=11,998 /\left(1+4,017 e^{-0,04647 D}\right)$ & $R^{2}=0,99$ \\
OPCOT & $98 Y 30$ & $\hat{Y}=11,055 /\left(1+3,9637 e^{-0,05672 D}\right)$ & $R^{2}=0,98$ \\
OPCOT & TMG 1174 RR & $\hat{Y}=12,7969 /\left(1+4,602 e^{-0,05217 D}\right)$ & $R^{2}=0,97$ \\
OPCOT & TMG 4185 & $\hat{Y}=10,9803 /\left(1+4,1834 e^{-0,06046 D}\right)$ & $R^{2}=0,97$
\end{tabular}

${ }^{1}$ COT: Diâmetro do hipocótilo no sentido dos cotilédones; OPCOT: Diâmetro do hipocótilo no sentido oposto aos cotilédones.

Ao analisar o diâmetro do hipocótilo, Silva et al. (2016) identificaram coeficientes de variação iguais à $11,035 \%$ para experimento conduzido no inverno e $11,669 \%$ para o verão. Portanto, a precisão dos resultados, medida pelo coeficiente de variação experimental, está dentro da amplitude obtida no estudo já publicado. Para Silva et al. (2016) os valores de coeficiente de variação podem estar associados à não homogeneização desta característica durante o processo de desenvolvimento de cultivares.

Ao analisar dez cultivares de soja (BRS Carnaúba, BRS Candeia, BRS 278 RR, BRS 271 RR, BRS Tracajá, UFVTN 105 AP, TMG 401, BRSMG 68 (Vencedora), TMG 801 e FMT Tucunaré) quanto 
ao diâmetro do hipocótilo, no estádio V3, em duas épocas do ano: inverno e verão, Silva et al. (2016) identificaram efeito significativo para cultivares e concluíram que existem diferenças entre as cultivares para esta características analisadas nas duas épocas de semeadura. Efeitos significativos para cultivares foram identificados nos quatro experimentos do presente trabalho, o que demonstrou há diferença entre as médias, tanto para DH-COT quanto para DH-OPCOT, quando se analisou 3, 4, 6 e 28 cultivares de soja. Assim, torna-se possível afirmar que o diâmetro do hipocótilo pode ser considerado potencial variável para avaliar a variabilidade entre cultivares e ou genótipos em análise nos programas de melhoramento genético. Isto porque, Nogueira et al. (2008) ao analisar uma série de variáveis reportou que a condição necessária para que uma característica possa ser útil na diferenciação de cultivares é a existência de variabilidade genética. No entanto, deve-se considerar a necessidade de mais estudos com intuído de melhor entendimento sobre os efeitos de outros genótipos, de outras influências das condições ambientes e de suas interações.

A magnitude das estimativas dos coeficientes de determinação genotípico $\left(\mathrm{H}^{2}\right)$, para as duas variáveis nos dois estádios de desenvolvimento, sugerem que as cultivares apresentaram grande influência genética em detrimentos aos efeitos ambientais. Segundo Cruz (2005) o $\mathrm{H}^{2}$ é uma medida análoga à herdabilidade e expressa a variância fenotípica devida à variabilidade genética entre as médias dos tratamentos, de forma que, estimativas elevadas do $\mathrm{H}^{2}$ indicam que a maior parte da variação entre as médias de genótipos é de natureza genética (VENCOVSKY, 1987). E, a maior importância da herdabilidade em estudos genéticos de caráter métrico é o seu papel preditivo, no qual é expresso a confiança do valor fenotípico como guia do valor genético, ou o grau de correspondência entre o valor fenotípico e o valor genético de uma população ou de um conjunto de genótipos (FALCONER e MACKAY, 1996). Silva et al. (2016) encontraram valores de $\mathrm{H}^{2}$ iguais à $77 \%$ e $86,3 \%$, respectivamente para, experimentos conduzidos no verão e inverno, e afirmaram que diâmetro do hipocótilo apresenta ampla influência genética. Além disto, Andrade et al. (2010) sugeriram que, para os caracteres que apresentam alto componente genético em suas expressões fenotípicas, a obtenção de ganhos por seleção pode ser conseguida via seleção visual ou massal.

A redução acentuada no diâmetro do caule, em feijão-caupi, associada aos aumentos lineares no comprimento do epicótilo em resposta aos aumentos nas densidades de planta de feijão tem, como consequência, uma maior predisposição das plantas ao acamamento nas maiores densidades populacionais (BEZERRA et al., 2012). Posteriormente, Brito (2014) corroborou com esta afirmação reportando que o diâmetro do hipocótilo se relaciona diretamente com o tombamento das plantas, ou seja a sua redução tendem a aumentar a predisposição da planta ao tombamento.

Em soja, Pereira et al. (2009) reportaram que caso não haja resistência, na germinação, a plântula cresce normalmente em comprimento, conforme as suas propriedades genéticas e fisiológicas. Enquanto que, em solos com encrostamento superficial, Costa et al. (1999) concluíram que o engrossamento do hipocótilo pode ser uma adaptação favorável à emergência das plântulas sob pressão contrária e que hipocótilo com diâmetro maior torna a plântula mais competente em emergir nesta situação adversa. Portanto, diâmetro maior do hipocótilo pode ser interpretado como adaptação à superação da resistência à emergência da plântula (PEREIRA et al., 2009). Linzmeyer Junior et al. (2008) verificaram que houve influência da densidade de plantas sobre a altura e o diâmetro de caule das plantas, ou seja os tratamentos com 14 plantas por metro apresentaram menor altura e diâmetro de caule em relação aos de 18 plantas e, também, reportaram que maior densidade de plantas acarretou aumento da altura e redução do diâmetro do caule. Nepomuceno e Silva (1992) atribuem este fato à maior competição intraespecífica das plantas, por luz incidente. No presente trabalho, a profundidade de semeadura não influenciou o diâmetro do hipocótilo, o que indica que nas condições de condução do experimento (profundidades de 1, 2 e $3 \mathrm{~cm}$ ) não resultaram em pressão contrária significativa que implicasse na necessidade de a plântula aumentar o 
diâmetro do hipocótilo para se adaptar visando a superação da resistência proporcionado pelo solo. Ressalta-se que este estudo foi realizado em condições controlada de casa de vegetação e que o comportamento do diâmetro do hipocótilo das cultivares pode ser diferente quando analisadas em condições de campo.

As magnitudes das correlações fenotípicas entre os pares de variáveis: DH-COT-V2 x DHOPCOT-V2, DH-COT-V2 x DH-COT-V3, DH-COT-V2 x DH-OPCOT-V3, DH-OPCOT-V2 x DH-COTV3, DH-OPCOT-V2 x DH-OPCOT-V3 e DH-COT-V3 x DH-OPCOT-V3 foram superiores ou igual à 0,80 , positivas e significativas (Tabela 9).

Tabela 9. Estimativas de correlações simples (rfe) e genotípicas (rge) entre quatro caracteres avaliados em 28 cultivares de soja, cultivados em casa de vegetação ${ }^{1}$

\begin{tabular}{lcc}
\hline \multicolumn{1}{c}{ Pares de caracteres } & rfe & rge \\
\hline DH-COT-V2 x DH-OPCOT-V2 & $0,92 * *$ & $0,97++$ \\
DH-COT-V2 x DH-COT-V3 & $0,88 * *$ & 0,97 \\
DH-COT-V2 x DH-OPCOT-V3 & $0,91 * *$ & 0,98 \\
DH-OPCOT-V2 x DH-COT-V3 & $0,80 * *$ & 0,97 \\
DH-OPCOT-V2 x DH-OPCOT-V3 & $0,91 * *$ & 0,98 \\
DH-COT-V3 x DH-OPCOT-V3 & $0,91 * *$ & $0,98++$ \\
\hline
\end{tabular}

${ }^{1 / * *}$ e $*$ : Significativo a 1 e $5 \%$ de probabilidade pelo teste $\mathrm{t} ;++\mathrm{e}+:$ Significativo a 1 e $5 \%$, respectivamente, pelo método de bootstrap com 5000 simulações

Isto indica que, por exemplo, para o par DH-COT-V2 x DH-OPCOT-V2, plantas no estádio V2 com alto valor para diâmetro do hipocótilo (sentido cotilédones) também apresentam alto valor para diâmetro do hipocótilo (sentido oposto aos cotilédones). Assim, a seleção para plantas com alto valor de DH-COT resultaria na seleção indireta de plantas com alto valor de DH-OPCOT.

A correlação fenotípica pode ser diretamente mensurada a partir de medidas de dois caracteres em um certo número de indivíduos da população e a correlação fenotípica tem causas genéticas e ambientais (CRUZ et al., 2004). Conforme Falconer e Mackay (1996), a correlação genética tem duas causas, uma devido à pleiotropia, causa principal, e a outra ocasionada pela ligação gênica, causa temporária. Os valores obtidos para correlação genotípica foram superiores ou iguais à 0,97 , positivos e somente os pares DH-COT-V2 x DH-OPCOT-V2 e DH-COT-V3 x DH-OPCOT-V3 foram significativos. Se dois caracteres apresentem correlação genética favorável, é possível obter ganhos para um deles por meio da seleção indireta do outro associado (CRUZ et al., 2004). Assim, os resultados indicam que o diâmetro do hipocótilo pode ser mensurado em apenas um sentido (sentido dos cotilédones ou sentido oposto aos cotilédones), quando fixado o estádio de desenvolvimento.

\section{CONCLUSÃO}

As cultivares de soja se diferenciam quanto ao diâmetro do hipocótilo e foi identificado grande influência genética em detrimentos aos efeitos ambientais.

Semeadura de 1 a $3 \mathrm{~cm}$ de profundidade não influenciou o diâmetro do hipocótilo, avaliados nos estádios V2 e V3, ao analisar plantas das cultivares TMG 4185, BRSMG 68 [Vencedora], BRS 7980 e BRS 8381. 
As cultivares 98Y30, TMG1174RR e TMG 4185 apresentaram comportamento semelhantes quanto ao diâmetro do hipocótilo no período de 0 à 48 dias após o estádio de desenvolvimento V1.

\section{AGRADECIMENTOS}

Ao CNPq (Conselho Nacional de Desenvolvimento Científico e Tecnológico) e à FAPEMIG (Fundação de Amparo à Pesquisa do Estado de Minas Gerais) pelo apoio financeiro.

\section{REFERÊNCIAS}

ANDRADE, F. N.et al. Estimativas de parâmetros genéticos em genótipos de feijão-caupi avaliados para feijão fresco. Revista Ciência Agronômica, Fortaleza, v. 41, n. 2, p. 253-258, 2010.

BEZERRA, A.A.C.et al. Comportamento morfoagronômico de feijãocaupi, cv. BRS Guariba, sob diferentes densidades de plantas. Revista de Ciências Agrárias, Belém, v.55, n.3, p.184-189, 2012.

BRITO, L.C.R. Comportamento de cultivares de feijão-caupi de porte semiprostrado em resposta à diferentes densidades de plantas. 2014. 90p. Dissertação (Agronomia - Produção Vegetal), Universidade Federal do Piauí, Piauí, 2014.

CHAVES, M.V.A.et al. Genotype x environment interaction and stability of soybean cultivars for vegetative-stage characters. Genetics and Molecular Research, v.16, gmr16039795, 2017.

COSTA, J.A.et al. Comprimento e índice de expansão radial do hipocótilo de cultivares de soja. Ciência Rural, Santa Maria, v.29, n.4, p.609-612, 1999.

CRUZ, C. D. Princípios de genética quantitativa. Viçosa: UFV, 2005, 394p.

CRUZ, C. D.; REGAZZI, A. J.; CARNEIRO, P. C. S. Modelos biométricos aplicados ao melhoramento genético. v.1, 3 ed. Viçosa: UFV, 2004, 480p.

CRUZ, C.D. Genes: a software package for analysis in experimental statistics and quantitative genetics. Acta Scientiarum. Agronomy, Maringá, v.35, n.3, p.271-276, 2013.

DIAS, S.H.B.et al. Repeatability analysis on morphological descriptors in the early stages of development African Journal of Agricultural Research, v.12, n.30, p.2442-2451, 2017

FALCONER, D. S.; MACKAY, T. F. C. Introduction to quantitative genetics, Ed. 4. Longmans Green, Harlow, Essex, UK, 1996, 464p.

FEHR, W.R.; CAVINESS, C.E. Stage of soybean development. Ames: Iowa State University of Science and Technology, 1977. 11p. (Special report 80).

FERRAZ e CAMPOS, S.R.et al. Registro e Proteção de Cultivares. In: SEDIYAMA, T. Tecnologia de produção e usos da soja. Londrina: Mecenas, 2009, p.235-245.

KNITTLE, K.H.; BURRIS, J.S. Soybean hypocotyl growth under field conditions. Crop Science, Madison, v.19, n.1, p.37-41, 1979.

LINZMEYER JUNIOR, R.et al. Influência de retardante vegetal e densidades de plantas sobre o crescimento, acamamento e produtividade da soja. Acta Scientiarum. Agronomy, vol. 30, núm. 3, pp. 373-379, 2008, 
MAPA/SNPC. Ministério da Agricultura Pecuária e Abastecimento / Serviço Nacional de Proteção de Cultivares. Cultivares protegidas. Brasília - DF, 2018. Disponível em:

<http://sistemas.agricultura.gov.br/snpc/cultivarweb/cultivares_protegidas.php> Acesso em: 03 out. 2018.

MATSUO, E.et al. Estimates of the genetic parameters, optimum sample size and conversion of quantitative data in multiple categories for soybean genotypes. Acta Scientiarum. Agronomy, Maringá, v.34, n.3, p.265-273, 2012a

MATSUO, E.et al. Análise da repetibilidade em alguns descritores morfológicos para soja. Ciência Rural, Santa Maria, v.42, n.2, p.189-196, 2012b

NOGUEIRA, A.P.O.et al. Novas características para diferenciação de cultivares de soja pela análise discriminante. Ciência Rural, Santa Maria, v.38, n.9, p.2427-2433, 2008.

NEPOMUCENO, A.L.; SILVA, P.R.F. Efeito do arranjo de plantas e da presença de ervas daninhas nas características de plantas associadas à colheita de girassol. Pesquisa Agropecuária Brasileira, Brasília, v. 27, n. 7, p. 1057-1063, 1992.

ODA, M.C.et al. Phenotypic and molecular traits diversity in soybean launched in forty years of genetic improvement. Agronomy Science and Biotechnology, Londrina, v.1, n.1, p.1-9, 2015

PEREIRA, W.A.et al. Influência da disposição, número e tamanho das sementes no teste do comprimento de plântulas de soja. Revista Brasileira de Sementes, Londrina, v.31, n.1, p.113-121, 2009

SAEG. SAEG: Sistema para Análises Estatísticas, versão 9.1, Viçosa: UFV, 2007.

SILVA, F.C.S.et al. Identification of new descriptors for differentiation of soybean genotypes by Gower algorithm. African Journal of Agricultural Research, v.11, n.11, p. 961-966, 2016

VASCONCELOS, E.S.et al. Estimativas de parâmetros genéticos da qualidade fisiológica de sementes de genótipos de soja produzidas em diferentes regiões de Minas Gerais. Semina: Ciências Agrárias, Londrina, v.33, n.1, p.65-76, 2012

VENCOVSKY, R. Herança quantitativa. In: PATERNIANI, E.; VIEGAS, G. P. (Ed.). Melhoramento e produção de milho. Campinas: Editora Fundação Cargil, 1987. p. 135-214. 